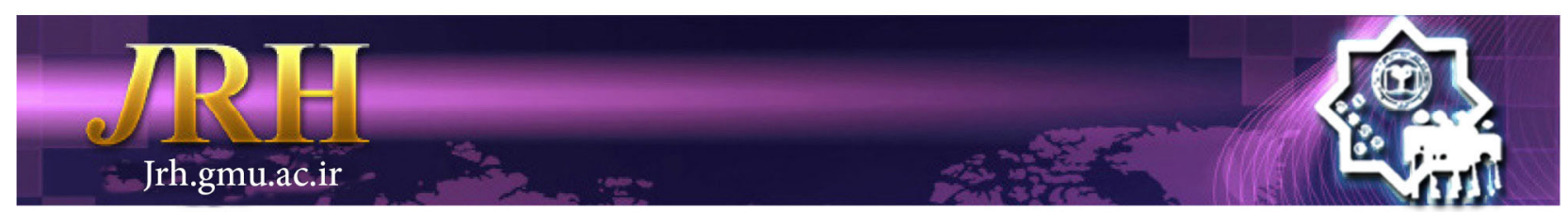

\title{
Predictive role of mindfulness in externalizing disorders among adolescents
}

Azadeh Samarghandi ${ }^{1}$, Ali Mashhadi ${ }^{1}$, Zohreh Sepehri Shamloo ${ }^{1}$

\author{
Journal of Research \& Health \\ Social Development \& Health Promotion \\ Research Center \\ Vol. 9, No. 6, Nov \& Dec 2019 \\ Pages: 463 - 470 \\ DOI: $10.32598 /$ jrh.9.6.463 \\ Original Article
}

1. Department of Psychology, Faculty of Education Sciences and Psychology, Ferdowsi University of Mashhad, Mashhad, Iran

Correspondence to: Ali Mashhadi, Department of Psychology, Faculty of Education Sciences and Psychology, Ferdowsi University of Mashhad, Mashhad, Iran

Email:mashhadi@um.ac.ir

Received: 21 May 2016 Accepted: 3 Agu 2017

How to cite this article: Samarghandi A, Mashhadi A, Sepehri Shamloo Z. Predictive role of mindfulness in externalizing disorders in adolescents. $J$ Research \& Health2019; $9(6): 463-470$

\begin{abstract}
Interest in the use of mindfulness-based activities with youth is growing. Students with externalized disorders often have problems with mindfulness and attention activities. The relationship between mindfulness and externalizing problems in children and adolescents has important therapeutic implications. This study was designed to investigate the predictive role of mindfulness in externalizing disorders among adolescents. In this study, 250 high school students were selected. In order to measure the mindfulness characteristics, mindfulness attention awareness scale brown \& ryan and to measure externalizing disorders, youth self-report of Achenbach's self-report form were used was. There was a significant inverse relationship between score of mindfulness and total score of externalizing problems. In addition, there was a significant inverse relationship between mindfulness and components related to externalizing problems (lawlessness, aggression, problems with attention deficit/ hyperactivity, oppositional defiant disorder issues and problems associated with conduct disorder). Regression analysis showed that mindfulness with $19 \%$ of variance explained can predict symptoms of externalizing disorders. The results showed Mindfulness has significant negative correlation with externalizing disorders symptoms and also mindfulness is able to predict symptoms of externalizing disorders.
\end{abstract}

Keywords: Adolescents, Behaviors, Disorders, External, Mindfulness

\section{Introduction}

Adolescence as the period of transition from childhood to adulthood has special sensitivities. In this period, the adolescent face individual, social and family problems on the one hand and extensive physical and cognitive changes on the other hand [1].

Adolescence is particularly known as a critical period for psychopathology growth, so that people experience many changes including changes in individual's social context and developmental changes associated with maturity. These developmental changes beside other typical stressors lead to increase negative effects and inability of emotional self-regulation which ultimately can predict the incidence of psychopathology [2,3]. One important point that since all adolescents don't experience the adverse consequences in response to disorder but it reflects the fact that there are individual underlying factors in the relationship between responses to the negative effects of this period of life and mental pathology in adolescents [4]. After several decades of research on psychopathology and contrary to initial belief, it has been shown that children and adolescents are also at increased risk of psychological 
problems and in total, $14 \%$ to $22 \%$ of children and adolescents are grappling with a variety of emotional and behavioral problems [5].

Childhood and adolescence disorders are divided into two main categories as externalizing disorders involving two groups of law breaking and aggressive behaviors and including attention deficit / hyperactivity disorder, conduct disorder and oppositional defiant disorder and internalizing disorders including disorders which reflect individual's symptoms such as depression, anxiety and physical complaints [6]. According to Achenbach and Rescorla externalizing disorders include problems that are facing outward and are in conflict with other people and the environment. On the contrary, the main characteristics of internalizing disorders are too inhibited behaviors that are directed inward [7]. The symptoms of externalizing and internalizing problems usually appear during adolescence and are associated with dysfunction, high risk of severe psychological damage and loss of mentalsocial function - during adulthood [8].

In Ackerson's classification, behavioral problems, aggressive behavior and delinquency are classified into externalizing problems [9]. Marchant et al. stated that externalizing symptoms involve behavioral disorders and aggression [10]. Liu described the behavioral problems of externalizing as the explicit behaviors that have negative effects on the external environment [11]. Studies in the field of externalizing disorders revealed a common trajectory consistent with developmental patterns for these disorders all of which focus on impulsive features. The impulsive features might grow as normal personality features, massive disorder, or unusual actions which can be influenced by internal factors such as weak emotional regulation skills, low Intelligence Quotient (IQ) or external factors such as family dynamicity, suffering in the early years of life, impact of peers and socialization [12]. One of the leading clinical factors in behavioral disorders is the problem of encountering with negative emotions [13] that several researchers have conceptualized behavioral disorders as the attempt to obtain regulation or to avoid negative emotions [14]. People who face difficulty in knowing and being aware of their current emotions and thoughts and feelings (as a more general example in relation to mindfulness) have probably certain problems in experiencing emotions, thoughts, and feelings with somewhat unpleasant potential. When people with low mindfulness cannot avoid such unpleasant experiences, they probably feel the need to suppress their experience with much effort which in turn can enhance behavioral disorders in them [15].

Mindfulness is a relatively new concept in Western psychology which is rooted in Eastern Buddhist traditions. This feature is defined as paying attention to the current experience and is a concept which can have a contributive or conditional quality. When mindfulness has an attributive feature it can be almost constant during time and when it has a conditional quality it is created through practice or training [16]. Bishop et al. defined mindfulness as "attention self-regulation as far as it remains on immediate experience and has the features of curiosity, openness, and acceptance" [17]. At present, mindfulness is defined as a multidimensional nature. Low mindfulness is very important and plays important role in range of disorders including behavioral disorders (such as externalizing disorders). Mindfulness levels are inversely associated with self-reports of verbal and physical aggression [18,19]. In addition, the increase of mindfulness predicts the decrease of behavioral problems in an attempt to change motivated emotions in disturbing situations. This relationship has been achieved in both clinical and non-clinical populations [20,21].

Mindfulness is a multidimensional structure whose operational difficulty has been proved consists of some concepts such as nonjudgment, acceptance, and awareness of the present moment, attention and intention. These components must be present for the experiencing of mindfulness [22]. In other words, mindfulness points out a sort of emotional and intellectual re-concentration through non-judgmental concentration on thoughts and feelings and other immediate 
aspects of the environment by making every moment of feelings dissociation and unpleasant thoughts of the individual [23]. The research literature about mindfulness and externalizing behaviors in adolescents showed very positive results. Moreover, the theoretical importance of the relationship between mindfulness exercises and different behaviors can always be seen in studies. Therefore, mindfulness can play important role in many situations of individuals' mental health [24].

Mindfulness is associated with high levels of life satisfaction [25], agreeableness [26], loyalty [26], vitality [25], self-confidence [25,27], and sense of independence, competence, optimism, and positive affection. The relationship between negative impulsivity and mindfulness has also been proved [25]. Lattimor, Fisher, and Malinowski investigated disinhibition and its association with mindfulness and impulsivity in individuals with eating disorder [28].

In study of Smalley et al, level of mindfulness in patients with Attention Deficit Hyperactivity Disorder (ADHD) has been reported less than the ordinary person which is a kind of externalizing disorder [29]. Heppner et al. found that higher level of mindfulness is associated with less anger and hostility and verbal aggression which are all the symptoms of externalizing disorders [30]. In study of Singh et al , three adults with mental illness and three adolescents with behavior disorder participated in mindfulness skill training for four weeks. After that, they were asked to still continue mindfulness exercises. The incidence of aggressive and delinquent behavior was recorded for at least 25 weeks. For all the participants, aggression reduced or even disappeared [19]. Wang Tang Cam by training of mindfulness techniques and its enchantment it showed that aggression and hostility reduced in Thai youth after such trainings [31]. Molly Cairncross studied the effectiveness of mindfulness on externalizing disorders and particularly ADHD in a metaanalysis [32]. Abdollah Zadeh by mindfulness treatment in adolescents with ADHD showed that symptoms of the disorder decreased after mindfulness enchantment in adolescents [33]. As the act without awareness is considered as the manifestation of impulsive behavior, act with awareness as the main feature of mindfulness, on the contrary can have a negative relationship with similar features [25]. Since impulsive and aggressive behaviors are the main features of adolescents with externalizing disorders, the low mindfulness of such individuals might be concluded accordingly. Considering the mentioned points in relation to the symptoms of externalizing disorders and the problems resulting from them and since that adolescent are considered as very sensitive group they were selected for study in this research. In addition, since the role of mindfulness has been less emphasized in studying the factors affecting externalizing disorders, the present study was carried out to determine between mindfulness and externalizing problems in adolescents.

\section{Method}

This study is an analytical research. The research population included all first grade high school girls in Mashhad in 2014-2015 academic years. 300 participants were selected using random cluster sampling. Seven area was selected from among Mashhad's education districts. Three schools were selected in the area and then three classes were selected within each school to collect data. This research was reviewed and approved by the Ethics Committee in faculty of education sciences and psychology at Ferdowsi University of Mashhad (ethical code: 1394.617). The participants were ensured to participate voluntarily and they were asked to answer all the questions carefully after explaining the aims of the research. After collecting all the questionnaires those were not fully completed were omitted and ultimately data for 250 respondents were entered into SPSS. Data analyzed by correlation and regression methods with SPSS-16. All analysis are statistically significant at $p<0.01$.

The following tools were used to collect the data:

Mindfulness Attention Awareness Scale (MAAS): The trait MAAS is a 15 -item scale was designed by Brown and Ryan to assess 
a core characteristic of mindfulness, namely, a receptive state of mind in which attention, informed by a sensitive awareness of what is occurring in the present, simply observes what is taking place. This is in contrast to the conceptually driven mode of processing, in which events and experiences are filtered through cognitive appraisals, evaluations, memories, beliefs, and other forms of cognitive manipulation. The scale's questions assess mindfulness structure in Likert's 6-point scale (from 1 for "almost always" to 6 for "almost never". This scale obtains a total score for mindfulness that ranges from 15 to 90 and higher score indicates higher mindfulness. The validity of the scale has been reported with regard to its negative correlation with measurement tools of anxiety and depression and its positive correlation with measurement tools of positive affection and adequate self-esteem. The Cronbach's alpha for the questions of the Farsi version of this scale for a sample of 723 subjects has been calculated as 0.81 [34].

Youth Self-Report (YSR) of Achenbach Form of Self-Reported Behavioral Problems: Youth Self-Report (YSR) of self-reported behavioral problems scale designed by Achenbach was used in order to measure externalizing problems in adolescents in this study. This scale can be responded in 15 minutes for ages 11 to 18 years with minimum education of the fifth grade of elementary school [35]. This scale includes qualifications and syndromes. The syndrome sector consists of 12 items including withdrawal/ depression, somatic complaints, depression/ anxiety, social problems, thought problems, attention problems, delinquent behavior, aggressive behavior as well as other behavioral problems which form a heterogeneous set of various problems such as behavior like the opposite sex, disobedience, not eating, fear of school, nightmares, overeating, overweight, etc. the validity of this questionnaire has been frequently investigated. The correlation coefficient of Youth Self-Report (YSR) scale with Junior Eysenck Personality Questionnaire ranges from 0.39 to 0.68 [35] and with the parent form of Chile Symptom Inventory (CSI4) ranges from 0.15 to 0.24 [36]. Moreover, the reliability coefficients of this questionnaire via Cronbach's alpha were 0.85 for general problems, [36], 0.93 and 0.9 [37].

\section{Results}

In this study which aimed to investigate the relationship between mindfulness and externalizing problems, of the 250 participants in the study on the basis of age, 32 participants were 13 years old (13\%), 133 participants were 14 years old (53\%), and 85 participants were 15 years old (34\%). According to the education level, 51 participants of the total subjects were studying in the seventh grade high school $(20 \%)$, and 199 participants in the eighth grade high school (80\%).

Themeanandstandarddeviation formindfulness as the predicting variable and externalizing problems as the criterion variables as well as Pearson correlation coefficients between mindfulness and externalizing problems are presented in Table 1.

Table 1 Mean, standard deviation and correlation of mindfulness and externalizing problems $(N=250)$

\begin{tabular}{|c|c|c|c|c|c|c|c|c|c|}
\hline \multirow{2}{*}{ Variables } & \multirow{2}{*}{ Mean } & \multirow{2}{*}{$\mathrm{SD}$} & \multicolumn{7}{|c|}{ Correlation } \\
\hline & & & 1 & 2 & 3 & 4 & 5 & 6 & 7 \\
\hline $\begin{array}{l}\text { 1. Externalizing } \\
\text { problems }\end{array}$ & 13.53 & 8.39 & - & & & & & & \\
\hline 2. Aggression & 9.31 & 5.45 & $0.92 *$ & - & & & & & \\
\hline 3. Breaking the law & 4.15 & 3.69 & $0.84 *$ & $0.62 *$ & - & & & & \\
\hline $\begin{array}{l}\text { 4. Attention deficit/ } \\
\text { hyperactivity disorder }\end{array}$ & 5.04 & 2.90 & $0.68^{*}$ & $0.71 *$ & $0.48^{*}$ & - & & & \\
\hline $\begin{array}{l}\text { 5. Oppositional defiant } \\
\text { disorder }\end{array}$ & 3.27 & 2.27 & $0.79 *$ & $0.86^{*}$ & $0.51^{*}$ & $0.55^{*}$ & - & & \\
\hline 6. Conduct Disorder & 3.97 & 3.60 & $0.86^{*}$ & $0.72 *$ & $0.87 *$ & $0.51 *$ & $0.59 *$ & - & \\
\hline 7. Mindfulness & 66.62 & 13.39 & $-0.43 *$ & $-0.42 *$ & $-0.31 *$ & $-0.45^{*}$ & $-0.31 *$ & $-0.32 *$ & - \\
\hline
\end{tabular}


The data in Table 1 showed that there is a significant negative correlation between mindfulness and all externalizing problems. There is also a significant negative correlation between mindfulness and total score of externalizing problems.

Simple regression analysis was used to investigate the role of mindfulness in the total score of externalizing problems and each of these problems as a criterion variable. Therefore, in all equations, the presumption of use regression model was examined by Durbin/ Watson test for the assessment of the independence of errors (all amounts of Durbin Watson test were higher than 4; therefore, the results of regression models are reliable (Table 2).

The results of Table 2 showed that mindfulness has predicted externalizing problems with explaining $19 \%$ of its variance. Mindfulness could also explain 18\% of aggression scores variance, $0.09 \%$ of breaking the law scores variance; $20 \%$ of attention deficit/ hyperactivity disorder scores variance, $0.09 \%$ of oppositional defiant disorder scores variance and $0.10 \%$ of conduct disorder scores variance. It should be noted that all these values are statistically significant $(p<0.001)$. In other words, mindfulness can predict a significant and remarkable percentage of externalizing problems scores. Regression coefficients in Table 2 showed that all regression coefficients between mindfulness and externalizing problems are negative. The negative coefficients indicate the inverse relationship between the variables; that by increasing of mindfulness scores, externalizing problems scores would be decreased.

Table 2 Regression characteristics of mindfulness on externalizing problems $N=(250)$

\begin{tabular}{lcccccccc}
\hline Criterion variable & $\begin{array}{c}\text { Predicting } \\
\text { variable }\end{array}$ & R & R2 & Df & F & B & Beta & T \\
\hline Externalizing Problems & Mindfulness & 0.43 & 0.19 & $(248 \cdot 1)$ & $58.44^{*}$ & -0.27 & -0.43 & $-7.64^{*}$ \\
Aggression & Mindfulness & 0.42 & 0.18 & $(248 ، 1)$ & $55.16^{*}$ & -0.17 & -0.42 & $-7.42^{*}$ \\
Breaking the law & Mindfulness & 0.31 & 0.09 & $(248 \cdot 1)$ & 26.77 & -0.08 & -0.31 & $-5.17^{*}$ \\
Attention deficit/ hyperactivity disorder & Mindfulness & 0.45 & 0.20 & $(248 \cdot 1)$ & $64.03^{*}$ & -0.09 & -0.45 & $-8.00^{*}$ \\
Oppositional defiant disorder & Mindfulness & 0.31 & 0.09 & $(248 \cdot 1)$ & $26.92^{*}$ & -0.05 & -0.31 & $-5.18^{*}$ \\
Conduct disorder & Mindfulness & 0.32 & 0.10 & $(248 \cdot 1)$ & $29.73^{*}$ & -0.08 & -0.32 & $5.45^{*}$ \\
\hline${ }^{*}<0.001$ & & & & & & & &
\end{tabular}

\section{Discussion}

The results of the study showed that there is a significant and negative relationship between mindfulness and externalizing problems in adolescents. In other words, adolescents would have fewer externalizing problems with the higher mindfulness. Moreover, there is a significant and negative relationship between mindfulness and the subscales of externalizing problems including aggression, law breaking behaviors, ADHD problems, oppositional defiant disorders and conduct disorder. Furthermore, mindfulness can predict externalizing problems in adolescents and the predicting role of mindfulness in the subscales of externalizing problems can be seen in the study's results as well.
The results of this study are consistent with the studies of Wang Ting Cum who showed that the increasing of mindfulness could be significantly associated with the decline of anger and hostility in adolescents [31] as well as the study conducted by Molly Cairncross who showed the effectiveness of mindfulness in the reduction of externalizing problems symptoms in a meta-analysis [32] and Smalley et al. who reported the negative and significant relationship between mindfulness and ADHD which is one of the internalizing disorders [29]. The results are also consistent with the findings of Sign et al. that revealed that by aggressive and delinquent behaviors in adolescents with conduct disorder would 
be decreased by increasing of mindfulness [19] and with the findings of Usani and Laurens who caused the decrease of aggression and increase of self-control by increasing mindfulness skill in adolescents who harmed themselves and others by aggressive behaviors [38].

In general, mindfulness can be considered as a protection against psychological disorders [39]. Given that externalizing behaviors are considered some kind of short term relief for individuals, those with internalizing disorders always receive a kind of negative reinforcement which in turn increases the probability of repeating such behaviors in them so that they ultimately change into automatic reactions against any sign of discomfort [15]. The feature of these automatic and somewhat repulsive reactions is "action without awareness" while the main feature of mindfulness is "action with full awareness". Therefore, it can be stated that individuals with externalizing problems report damage to mindfulness which can be the origin of their impulsive action as the low rate of this feature [33]. In order to explain these results in conjunction with the subscales of externalizing problems it can be said that in variables such as breaking the laws and in disorders such as oppositional defiant and conduct disorders, higher mindfulness in individuals can be associated with a kind of self-regulation in them. In other words, the self-regulation helps the individuals to produce positive emotional responses so that they assist the individuals to control their impulses. They also make the individuals to behave consciously to deal with the management of their emotions quite well. On the other hand, higher mindfulness makes individuals to focus more on situations including the elements of moral values and involving positive life and emphasis on the sympathy with others. In relation to negative correlation between mindfulness and aggression and its predicting role in aggressive behaviors it can be stated that one of the most important aspects of mindfulness is that those who report further mindfulness and own more mindfulness skills can deal with negative thoughts and emotion. In fact, their ability to tolerate negative emotional states will enhance which in turn increases their self-regulation and enables them to fight effectively [40].

On the other hand, the results of this research suggested that there is a negative and significant relationship between ADHD symptoms and mindfulness which indicates the fact that since mindfulness in behavioral level is associated with the increasing of ability to control attention and to decrease automatic responses, in individuals with high mindfulness there is more awareness of non-judgmental look and moment and, on the contrary, there are fewer automatic responses which can lead to impulsivity. Moreover, cognitive damage in executive actions including attention, working memory, and inhibition ability widely emphasized in individuals with ADHD is followed by problems in the motivation and regulation of emotion in such group of people while individuals who report higher mindfulness have more emotional regulation and attention which are followed by acceptance and curiosity through reduction of excitation and lack of involvement with experience and allowing it to pass.

This study was faced with some limitations such as the nature of the project. It is a co-relational study so it is not possible to achieve an overall conclusion through such a project and the relationship between variables is investigated in a non- causal way. Moreover, since the study has been carried out on students it is not possible to generalize the findings to other groups and populations. With regard to the results of the present research and since mindfulness is one of the effective factors on improvement of mental health and also it is a skill which can be trained so it's recommended for future studies to focus on projects related to training these skills. Furthermore, consistent with the findings of this study therapeutic protocols can be used based on mindfulness as well as training mindfulness techniques in order to treat students with eternalizing problems and to improve their mental health.

\section{Conclusion}

The results of this study show that there is an inverse and significant correlation between 
mindfulness and externalizing problems. Mindfulness is able to predict the symptoms of externalizing problems. Mindfulness training can be used as a new treatment for attention and impulsivity problems in adolescents with a variety of different externalizing disorders. Adolescent with externalizing disorders have problems with attention and behavioral control that may result from common underlying deficits in information processing. Mindfulness training, which directly addresses attention and impulsivity problems, may be an effective approach. Future studies could look at the application of mindfulness in school settings and the application of mindfulness as an early intervention to provide social and formal support for adolescent with externalizing problems and their parents.

\section{Acknowledgments}

The authors thank all the students, parents and teachers who participated in the study.

\section{Authors' contributions}

Study design: AS, AM, ZS

Data collection and analysis: AS

Manuscript preparation: AS, AM, ZS

All authors have read and approved the final version.

\section{Conflict of Interest}

"The author declares that they have no competing interests."

\section{Funding}

The author (s) received no financial support for the research, authorship and/or publication of this paper.

\section{Availability of data and materials}

The datasets used and/or analyzed during this study are available from the corresponding author on reasonable request.

\section{References}

1- Mogler C. Adolescence: The physical, cognitive, social, personality, moral, and faith development of adolescence. Munich: GRIN Verlag; 2009.

2- King KM, Chassin L. Adolescent stressors, psychopathology, and young adult substance dependence: A prospective study. J Stud Alcohol Drugs2008; 69(5): 629-38.

3- Sontag LM, Graber JA, Brooks-Gunn J, Warren MP. Coping with social stress: Implications for psychopathology in young adolescent girls. J Abnorm Child Psychol2008; 36(8): 1159-74.

4- Daughters SB, Gorka SM, Magidson JF, MacPherson L, Seitz-Brown CJ. The role of gender and race in the relation between adolescent distress tolerance and externalizing and internalizing psychopathology. $J$ Adolesc2013; 36(6): 1053-65.

5- Zeng G. An exploratory investigation of the internalizing problem behavior among children from kindergarten to third grade. Pennsylvania US: University of Pennsylvania; 2007.

6- Crawford NA, Schrock M, Woodruff-Borden J. Child internalizing symptoms: contributions of child temperament, maternal negative affect, and family functioning. Child Psychiatry Hum Dev2011; 42(1): 53-64.

7- Achenbach TM, Rescorla L. Manual for the ASEBA school-age forms \& profiles: An integrated system of multi-informant assessment. Burlington, VT: Aseba; 2001.

8- Colman I, Wadsworth ME, Croudace TJ, Jones PB. Forty-year psychiatric outcomes following assessment for internalizing disorder in adolescence. Am J Psychiatry2007;164(1):126-33.

9- Bakhtiari M, Yazdandost R, Birashk B, Ghazi Tabatabie M. Relationship between controlrelated beliefs with externalizing and internalizing psychopathology in children. Iraninan Psychiatry and Clinical Psychology2007; 2: 140-7.

10- Marchant MR, Solano BR, Fisher AK, Caldarella P, Young KR, Renshaw TL. Modifying socially withdrawn behavior: A playground intervention for students with internalizing behaviors. Psychol Sch2007; 44(8): 779-94. 11- White R, Renk K. Externalizing behavior problems during adolescence: An ecological perspective. J Child Fam Stud2012; 21(1): 158-71.

12- Frodl T, Skokauskas N. Neuroimaging of externalizing behaviors and borderline traits. Biol Psychiatry2014; 75: 7-8.

13- Anestis MD, Selby EA, Crosby RD, Wonderlich SA, Engel SG, Joiner TE. A comparison of retrospective self-report versus ecological momentary assessment measures of affective lability in the examination of its relationship with bulimic symptomatology. Behav Res Ther2010; 48(7): 607-13.

14- Baker TB, Piper ME, McCarthy DE, Majeskie MR, Fiore MC. Addiction motivation reformulated: an affective processing model of negative reinforcement. Psychol Rev2004; 111(1): 33. 
15- Wupperman P, Marlatt GA, Cunningham A, et al. Mindfulness andmodification therapy for behavioral dysregulation: results from a pilot study targeting alcohol use and aggression in women. J Clin Psychol2012; 68(1): 50-66.

16- Brown KW, Ryan RM, Creswell JD. Mindfulness: Theoretical foundations and evidence for its salutary effects. Psychol Inq2007; 18(4): 211-37.

17- Bishop SR, Lau M, Shapiro S, et al. Mindfulness: A proposed operational definition. Clinical Psychology: Science and Practice2004; 11(3): 230-41.

18- Borders A, Earleywine M, Jajodia A. Could mindfulness decrease anger, hostility, and aggression by decreasing rumination? Aggress Behav2010; 36(1): 28-44. 19- Singh NN, Lancioni GE, Joy SD, et al. Adolescents with conduct disorder can be mindful of their aggressive behavior. J Emot Behav Disord2007; 15(1): 56-63.

20- Wupperman P, Neumann CS, Axelrod SR. Do deficits in mindfulness underlie borderline personality features and core difficulties. J Pers Disord2008; 22(5): 466-82.

21- Wupperman P, Neumann CS, Whitman JB, Axelrod $\mathrm{SR}$. The role of mindfulness in borderline personality disorder features. J Nerv Ment Dis2009; 197(10): 766-71. 22- Mohammad Khani P, Khanipour H. Mindfulnessbased cognitive therapy (Mindfulness-based cognitive therapy along with practical guidelines for the prevention of recurrence of depression). Tehran: Social welfare and rehabilitation university sciences Publisher; 2010.

23- Swart J, Apsche J. Mindfulness, mode deactivation, and family therapy: A winning combination for treating adolescents with complex trauma and behavioral problems. Int J Behav Consult Ther2014; 9(2): 9.

24- Wisner BL, Jones B, Gwin D. School-based meditation practices for adolescents: A resource for strengthening self-regulation, emotional coping, and self-esteem. Child Sch2010; 32(3): 150-9.

25- Brown KW, Ryan RM. The benefits of being present: mindfulness and its role in psychological well-being. $J$ Pers Soc Psychol2003; 84(4): 822.

26- Thompson BL, Waltz J. Everyday mindfulness and mindfulness meditation: Overlapping constructs or not? Pers Individ Dif2007; 43(7): 1875-85.

27- Rasmussen MK, Pidgeon AM. The direct and indirect benefits of dispositional mindfulness on self-esteem and social anxiety. Anxiety Stress Coping2011; 24(2): 227-33. 28-Lattimore P, Fisher N, Malinowski P. A cross-sectional investigation of trait disinhibition and its association with mindfulness and impulsivity. Appetite2011; 56(2): 241-8.
29- Smalley SL, Loo SK, Hale T, et al. Mindfulness and attention deficit hyperactivity disorder. $J$ Clin Psychol2009; 65(10): 1087-98.

30- Heppner WL, Kernis MH, Lakey CE, et al. Mindfulness as a means of reducing aggressive behavior: dispositional and situational evidence. Aggress Behav2008; 34(5): 486-96.

31- Wongtongkam N, Ward PR, Day A, Winefield AH. A trial of mindfulness meditation to reduce anger and violence in Thai youth. Int J Ment Health Addict2014; 12(2): $169-80$

32- Cairncross M, Miller CJ. The effectiveness of mindfulness-based therapies for ADHD: A meta-analytic review. J Atten Disord2016. pii: 1087054715625301

33- Abdollahzadeh Z. The effectiveness of mindfulness- based therapy in increasing mindfulness, reducing ADHD symptoms and improvement internalizing difficulties adolescents with attention deficit-hyperactivity disorder [dissertation]. Mashhad: Ferdowsi university 2014; pp:100.

34- Nejati V, Zabihzadeh A, Nikfarjam M. The relationship of mindfulness with sustained and selective attentional performance. Research in Cognitive and Behavioral Science2013; 2: 31-42.

35- Fadaie Z, Najafi M, Habibi Asgarabad M, Besharat MA. Confirmatory factorial structure, reliability and validity of the achenbach youth self-report Scale (YSR): monozygotic and dizygotic twins. Journal of Clinical Psycology2009; 1(1): 1-18.

36- Minaei A. Adaptation and standardization of child behavior checklist, youth self-report, and teacher report forms. Research on exceptional children. Spring2006; 6(1): 19 .

37- Zargar Y, Mohammadi Bahramabadi R, Bassak Negad S. A study of family processes as predictors of behavior problems among second grade high school students in Yasuoj. Journal of School Psychology2012; 1: $77-103$.

38- Yusainy C, Lawrence C. Relating mindfulness and self-control to harm to the self and to others. Pers Individ Dif2014 ;64: 78-83.

39- Pepping CA, O'Donovan A, Zimmer-Gembeck MJ, Hanisch M. Is emotion regulation the process underlying the relationship between low mindfulness and psychosocial distress? Aust J Psychol2014; 66(2): 130-8. 40- Dewi SY, Wiwie M, Sastroasmoro S, Purba JS, Pleyte WE, Haniman F. Effectiveness of mindfulness therapy among adolescent with conduct disorder in Jakarta, Indonesia. Procedia Soc Behav Sci2015; 165: 62-8.

Copyright(C) 2016 ASP Ins. This open-access article is published under the terms of the Creative Commons Attribution-NonCommercial 4.0 International License which permits Share (copy and redistribute the material in any medium or format) and Adapt (remix, transform, and build upon the material) under the Attribution-NonCommercial terms. 